\title{
Cross-Talk Between Nitrosative Stress, Inflammation and Hypoxia-Inducible Factor in Patients with Adrenal Masses
}

\author{
Barbara Choromańska' \\ Piotr Myśliwiec' \\ Tomasz Kozłowski \\ Magdalena Łuba' \\ Piotr Wojskowicz' \\ Jacek Dadan' \\ Hanna Myśliwiec ${ }^{2}$ \\ Katarzyna Choromańska ${ }^{3}$ \\ Katarzyna Makarewicz ${ }^{4}$ \\ Anna Zalewska (iD ${ }^{5}$ \\ Mateusz Maciejczyk (D) ${ }^{6}$ \\ 'Ist Department of General and \\ Endocrine Surgery, Medical University of \\ Bialystok, Bialystok, Poland; ${ }^{2}$ Department \\ of Dermatology and Venereology, \\ Medical University of Bialystok, Bialystok, \\ Poland; ${ }^{3}$ Department of Oral Surgery, \\ Medical University of Gdansk, Gdansk, \\ Poland; ${ }^{4}$ Regional Centre for Transfusion \\ Medicine in Bialystok, Bialystok, Poland; \\ ${ }^{5}$ Experimental Dentistry Laboratory, \\ Medical University of Bialystok, Bialystok, \\ Poland; 'Department of Hygiene, \\ Epidemiology and Ergonomics, Medical \\ University of Bialystok, Bialystok, Poland
}

Correspondence: Mateusz Maciejczyk Email mat.maciejczyk@gmail.com
Background: Adrenal masses are the most common of all human tumors. The role of nitrosative stress and inflammation in cancer development has already been demonstrated. However, it is not known whether they are involved in the pathogenesis of adrenal tumors. The aim of the study was to investigate a cross-talk between nitrosative stress, inflammation and hypoxia-inducible factor (HIF-1 $\alpha$ ) in 75 patients with different types of adrenal masses (non-functional incidentaloma, pheochromocytoma and Cushing's/Conn's adenoma).

Methods: The plasma concentrations of total nitric oxide (NO), S-nitrosothiols, peroxynitrite nitrotyrosine and the activity of serum myeloperoxidase (MPO) were measured spectrophotometrically, whereas concentrations of interleukin 1 beta (IL-1 $\beta$ ), tumor necrosis factor $\alpha$ (TNF- $\alpha$ ) and hypoxia-inducible factor 1 alpha (HIF-1 $\alpha$ ) were measured using commercial ELISA kits. The control group consisted of 50 healthy people matched by age and sex to the study group. The number of subjects was determined a priori based on our previous experiment (power of the test $=0.9 ; \alpha=0.05$ ).

Results: We found significantly higher nitrosative stress ( $\uparrow$ nitric oxide, $\uparrow$ peroxynitrite, $\uparrow$ S-nitrosothiols and $\uparrow$ nitrotyrosine) in the plasma of patients with adrenal tumors, which was accompanied by increased inflammatory ( $\uparrow$ myeloperoxidase, $\uparrow$ interleukin 1 beta and $\uparrow$ tumor necrosis factor $\alpha$ ) and hypoxia (HIF-1 $\alpha$ ) biomarkers. Peroxynitrite and nitrotyrosine were positively correlated with aldosterone level. Nitrosative stress was also associated with inflammation and HIF$1 \alpha$. Interestingly, plasma nitrotyrosine and serum MPO differentiated patients with adrenal tumor from healthy individuals with high sensitivity and specificity. Moreover, using multivariate regression analysis, we showed that $\mathrm{ONOO}^{-}$and IL-1 $\beta$ depended on cortisol level, while $\mathrm{ONOO}^{-}$, nitrotyrosine and HIF-1 $\alpha$ were associated with aldosterone. Unfortunately, none of the assessed biomarkers differentiated between tumor types studied, suggesting that the severity of nitrosative damage and inflammation are similar in patients with incidentaloma, pheochromocytoma, and Cushing's or Conn's adenoma.

Conclusion: Adrenal tumors are associated with increased protein nitration/S-nitrosylation and inflammation.

Keywords: adrenal tumors, nitrosative stress, nitric oxide, peroxynitrite, S-nitrosothiols, nitrotyrosine, myeloperoxidase, interleukin 1 beta, tumor necrosis factor, $\alpha$ hypoxiainducible factor

\section{Introduction}

Adrenal masses are usually benign neoplastic lesions detected accidentally during the diagnosis of other diseases. ${ }^{1}$ They are the most common of all human tumors, and the frequency of their detection continues to increase, especially with age. ${ }^{2,3}$ Although 
most of adrenal masses are hormonally inactive, some of them may contribute to the overproduction of cortisol, aldosterone or catecholamines. ${ }^{4,5}$ Even though, adrenocortical carcinomas are very rare, the risk of adrenal masses becoming malignant increases with tumor size. It is estimated that $25 \%$ of adrenal tumors larger than $6 \mathrm{~cm}$ may become malignant. ${ }^{6}$ An adrenal masses is associated not only with the risk of malignancy, but also with the development of metabolic disturbances. ${ }^{7-9}$ In patients with phaeochromocytoma, excessive secretion of catecholamines (dopamine, adrenaline and noradrenaline) may lead to the development of obesity and disorders of lipid and glucose metabolism, insulin resistance, diabetes and hypertension. ${ }^{7}$ Cushing's syndrome also leads to weight gain and, consequently, to the development of obesity and its metabolic complications, while Conn's syndrome is the cause of treatment-resistant hypertension. ${ }^{10,11}$ Nevertheless, due to the variety of adrenal tumors, their clinical symptoms are not specific and their diagnosis is difficult. The pathogenesis of adrenal masses is still not fully understood. Probably genetic factors have the greatest impact on the development of adrenal tumors. ${ }^{12,13}$ Indeed, the mutation of VHL/HIF axis is the risk factor of pheochromocytoma development. ${ }^{14}$ Hypoxia-induced factor (HIF-1) has various effects on tumor growth and metabolism, as well as metastasis, especially in cancer secreting catecholamines. $^{15}$

Recent studies emphasize the crucial role of oxidative stress (OS) in the development of cancer. ${ }^{16-18}$ The production of reactive oxygen (ROS) and nitrogen (RNS) species is an inherent process of the oxygen metabolism of cells associated with many physiological and pathological processes in the human body. ${ }^{19}$ OS is closely associated to nitrosative stress. ${ }^{20}$ Nitric oxide (NO) reacts with molecular oxygen, superoxide anion and metal cations, causing the formation of further reactive oxygen species. ${ }^{21,22}$ The excessive formation of ROS and RNS leads to oxidative and nitrosative damage to lipids, proteins and DNA. ${ }^{19,23}$ Proteins are particularly sensitive to the action of ROS and RNS because oxidation or nitrosylation of amino acid residues can lead to their denaturation, fragmentation and aggregation, resulting in impairment of their (proteins') function or even cell apoptosis. ${ }^{24,25}$ Peroxynitrite $\left(\mathrm{ONOO}^{-}\right)$is one of the most cytotoxic reactive forms of nitrogen and the factor with the greatest potential for protein oxidation. It is formed in the reaction of $\mathrm{NO}$ with $\mathrm{O}_{2}{ }^{-26,27}$ Interestingly, its formation is promoted by an increase in inducible NOS isoform (iNOS) activity. ${ }^{27} \mathrm{ONOO}^{-}$in reaction with amino acids leads to irreversible modifications of proteins, which results in the formation of carbonyl groups, as well as nitration, nitrosylation and dimerization of proteins. $^{28-30}$ Moreover, both the formation of modified proteins and an increase in NO concentration can lead to the disruption of many signaling pathways and the initiation of inflammatory processes. ${ }^{21,22,31}$ Indeed, $\mathrm{ONOO}^{-}$and protein nitration products activate the nuclear factor kappa $\mathrm{B}(\mathrm{NF}-\kappa \mathrm{B})$, which induces the secretion of interleukin 1 (IL-1), interleukin 6 (IL-6), interleukin 8 (IL-8) and tumor necrosis factor $\alpha(\mathrm{TNF}-\alpha)$, intercellular adhesion molecule 1 (ICAM-1), as well as nitric oxide synthase (NOS). ${ }^{32,33}$ This leads to self-driving further oxidative/nitrosative damage. ${ }^{34}$ NO is also the mediator of inflammation due to its enhancing effect of cyclooxygenases action. ${ }^{20} \mathrm{Up}$ to $20 \%$ of tumors are thought to be caused by inflammation. Cytokines produced in excess contribute to the transformation of healthy cells into neoplastic ones. ${ }^{35}$

In our previous study, we found impaired enzymatic and non-enzymatic antioxidant barrier as well as increased oxidative damage to lipids, proteins, and DNA/RNA in plasma, serum and urine in patients with adrenal tumor. ${ }^{36}$ This indicates a lack of effective protection against oxidative stress in patients with adrenal masses. So far, nothing is known about the role of nitrosative stress and inflammation in the development of adrenal tumors. Moreover, the diagnosis of adrenal tumors is often difficult, therefore the aim of this study was also to search their new diagnostic biomarkers.

\section{Materials and Methods}

The study was designed and conducted according to the Guidelines for Good Clinical Practice and the Declaration of Helsinki, as well as approved by the Bioethics Committee of the Medical University of Bialystok (permission code: R-I-002/66/2015, APK.002.341.2020). All participants of this study gave their informed consent.

75 patients (39 women and 38 men aged from 49 to 65 years) with adrenal masses diameter $>1 \mathrm{~cm}$ and $<8 \mathrm{~cm}$ were qualified for this study. Patients had been diagnosed at internal medicine departments with an endocrinology profile and underwent elective endoscopic adrenalectomy at the 1st Department of General and Endocrine Surgery at the University Hospital in Bialystok, Poland. Depending on the diagnosis, patients were divided into 3 groups: patients with non-functional incidentaloma $(\mathrm{n}=25)$, pheochromocytoma $(\mathrm{n}=25)$ and Cushing's/Conn's adenoma $(\mathrm{n}=25)$. In the adenoma subgroup, 14 patients suffered from Cushing's syndrome and 11 from Conn's syndrome. Patients diagnosed with Conn's syndrome were taking potassium or spironolactone 
(aldosterone receptor blocker) in the preoperative period. Patients with phaeochromocytoma were treated with doxazo$\sin$ (a selective alpha-1-adrenergic receptor blocker) for 10 to 14 days prior to surgery to avoid intraoperative hypertensive crisis. 26 patients had hypertension, that was diagnosed according to World Health Organizations guidelines. Hypertension was diagnosed if measuring on two different days the value of systolic (SBP) and/or diastolic (DBP) blood pressure was 140/90 ( $\mathrm{mmHg}$ ) or above. Blood pressure was measured on the non-dominant upper arm using Diagnosis UA-651 A\&D Medical apparatus. The cuff was put on tightly to the exposed arm, about $2-3 \mathrm{~cm}$ above the elbow flexion. Two measurements at intervals of several minutes were taken.

The control group consisted of 50 healthy people ( 25 women and 25 men aged 50 to 65) who underwent a dental follow-up examination at the Specialist Dental Clinic at the Medical University of Bialystok. None of the volunteers had periodontal disease (probing pocket depth $(\mathrm{PPD}) \leq 2$; bleeding on probing $(\mathrm{BOP})<15$ ) or active caries (decayed teeth $<1$ ). Their full blood counts and biochemical blood parameters (INR, $\mathrm{K}^{+}, \mathrm{Na}^{+}$, creatinine ALT and AST) were within the reference values.

Participants for both the control and study groups were uniformly classified on the basis of a negative history of the following diseases: cardiovascular diseases (other than hypertension), neoplastic diseases, autoimmune diseases (Hashimoto's disease, ulcerative colitis and Crohn's disease), diseases of the respiratory, genitourinary and digestive systems, metabolic diseases (insulin resistance, type 1 diabetes, mucopolysaccharidosis, osteoporosis and gout), infectious diseases (HIV/AIDS, hepatitis A, B or C), acute inflammation, abusing alcohol and smoking as well as pregnancy in women. All participants of the study denied taking antibiotics, glucocorticosteroids, nonsteroidal anti-inflammatory drugs and antioxidant supplements (including iron preparations) for three months prior to collecting material for the study. The clinical and laboratory characteristics of the control and study groups are shown in Table 1.

\section{Blood and Urine Collection}

The participants of the study declared, that they did not perform intense physical activity twenty-four hours before blood sampling. All blood samples from patients of control and study groups were collected in a fasting state into serum and EDTA tubes (SARSTEDT, S-Monovette) and centrifuged for 10 minutes at $4^{\circ} \mathrm{C}$ and $4000 \mathrm{rpm}$. The urine samples were collected from the first-morning portion of urine from the middle stream immediately after bedtime into a sterile

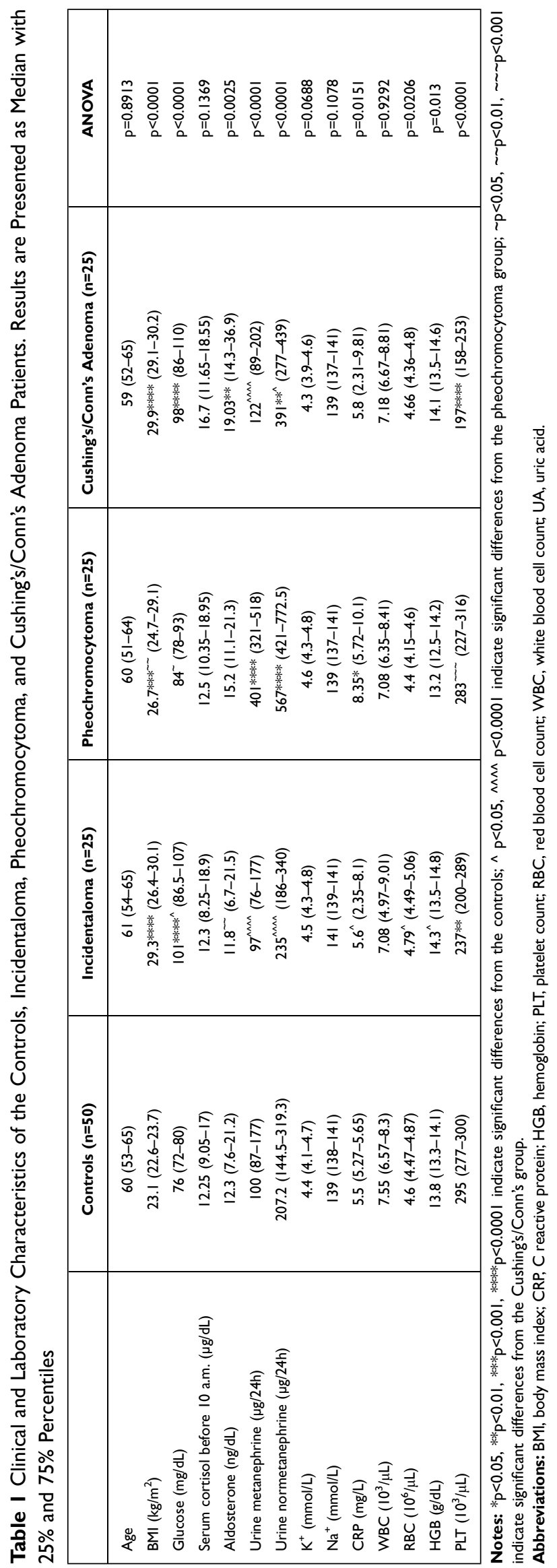


disposable container and centrifuged for 5 minutes at $1500 \mathrm{rpm}$. In order to protect against oxidation, butylated hydroxytoluene (BHT) was added to the supernatant $(10 \mu \mathrm{L}$ of $0.5 \mathrm{M} \mathrm{BHT} / 1 \mathrm{~mL}$ of plasma/serum and urine and stored at $-80^{\circ} \mathrm{C}$ until final examinations were made. ${ }^{16,37}$

\section{Laboratory Measurements}

Full blood count, as well as serum biochemical test (cortisol before 10 a.m., serum aldosterone, glucose $\mathrm{Na}^{+}, \mathrm{K}^{+}$, and urine metanephrine and normetanephrine) were determined using automated blood analyzers (Sysmex XN1000, Abbott Diagnostics, Wiesbaden, Germany). In both groups, the laboratory tests were performed in the Laboratory of Biochemical Diagnostics, University Hospital in Bialystok, Poland.

\section{Nitrosative Stress}

All reagents to this study were purchased from SigmaAldrich (Nümbrecht, Germany and/or Saint Louis, MO, USA). All determinations were conducted in duplicate samples and results were standardized to $1 \mathrm{mg}$ of total protein. NO concentration was determined in triplicates. The total protein content was analyzed spectrophotometrically using the bicinchoninic acid (BCA) method. Commercial diagnostic kit (Thermo Scientific PIERCE BCA Protein Assay; Rockford, IL, USA) was performed according to manufacturer's instructions. The absorbance and fluorescence were measured using BioTek Synergy H1 (Winooski, VT, USA) Microplate Reader.

The plasma concentration of total nitric oxide (NO) was measured spectrophotometrically method, using sulfanilamide and $\mathrm{NEDA} \cdot 2 \mathrm{HCl}$ (N-(1-naphthyl)-ethylenediamine dihydrochloride). ${ }^{38,39}$ The plasma concentration of S-nitrosothiols was evaluated spectrophotometrically in the reaction of the Griess reagent with $\mathrm{Cu}^{2+}$ ions. ${ }^{40}$ The concentration of plasma peroxynitrite was estimated spectrophotometrically according to the reaction of peroxynitrite-mediated nitration resulting in the formation of nitrophenol. ${ }^{41}$ The absorbance of NO and S-nitrosothiols was measured at 490 $\mathrm{nm}$, whereas peroxynitrite at $320 \mathrm{~nm}$. The concentration of plasma nitrotyrosine was analyzed spectrophotometrically using ELISA method. Commercial diagnostic kit (Immundiagnostik AG; Bensheim, Germany) was conducted in accordance with manufacturer's instructions.

The activity of serum myeloperoxidase (MPO) was measured spectrophotometrically at $450 \mathrm{~nm}$. The sulfanilamide hexadecyl trimethyl ammonium, ortho-dianisidine dihydrochloride, and hydrogen peroxide were used as reagents. $^{42}$ The concentrations of interleukin 1 beta (IL$1 \beta)$, tumor necrosis factor $\alpha(\mathrm{TNF}-\alpha)$ and hypoxiainducible factor 1 alpha (HIF-1 $\alpha$ ) were measured using commercial ELISA kits from EIAab, Wuhan, China. We followed the instructions provided by the manufacturer.

\section{Statistical Analysis}

Statistical analysis was performed using the GraphPad Prism 8.4.3 for MacOS (GraphPad Software, Inc. La Jolla, USA) according to Shapiro-Wilk test, Levene's test, KruskalWallis ANOVA test and post-hoc Dunn's test. Statistical significance was established at $\mathrm{p} \leq 0.05$ and multiplicityadjusted p-values were calculated for all comparisons. Data was expressed as median with $25 \%$ and $75 \%$ percentiles. Relations between various parameters were tested by Spearman correlation coefficient. Multivariate analysis of the simultaneous impacts of many independent variables on one quantitative dependent variable was conducted by means of linear regression. Cortisol, metanephrine, normetanephrine and aldosterone were included as independent variables. A 95\% CI was reported along with regression parameters. Based on receiver operating characteristic (ROC) curves, the diagnostic value of the analyzed biomarkers, ie, sensitivity and specificity of the test, was evaluated. The number of subjects was determined based on our previous experiment, assuming that the power of the test $=0.9$ and $\alpha=0.05$. ClinCalc online calculator was used to estimate the sample size.

\section{Results}

Table 1 shows a comparison of the clinical and laboratory characteristics of the controls and patients with adrenal masses. BMI of patients with adrenal masses was higher than the controls. Serum glucose concentration was increased in incidentaloma and Cushing's/Conn's adenoma patients compared to the healthy controls. In Cushing's/ Conn's adenoma patients the serum concentration aldosterone was greater than the controls. Additionally, aldosterone level was higher in Cushing's/Conn's adenoma in comparison with incidentaloma patients. Urinary concentrations of metanephrine and normetanephrine were higher in pheochromocytoma group as compared to other groups. The CRP level was greater pheochromocytoma than the controls and incidentaloma patients. We found content of PLT in patients with incidentaloma and Cushing's/Conn's adenoma as compared to the controls. Moreover, patients with Cushing's/Conn's adenoma have greater amount of PLT than pheochromocytoma one. 


\section{Total Plasma Nitric Oxide (NO)}

NO total plasma concentration of Cushing's Conn's adenoma was increased $(+131 \%, p=0.0018)$ as compared to the controls. Additionally, we found significantly lower plasma concentration of total $\mathrm{NO}$ in incidentaloma $(-71 \%, \mathrm{p}=0.0015)$ and pheochromocytoma $(-55 \%, p=0.0174)$ than Cushing's Conn's adenoma patients (Figure 1A).

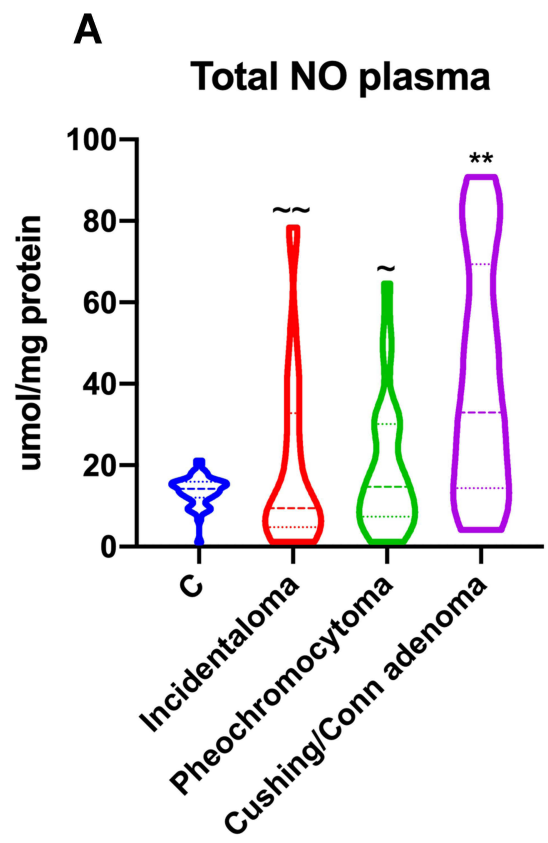

C

S-nitrosothiols plasma

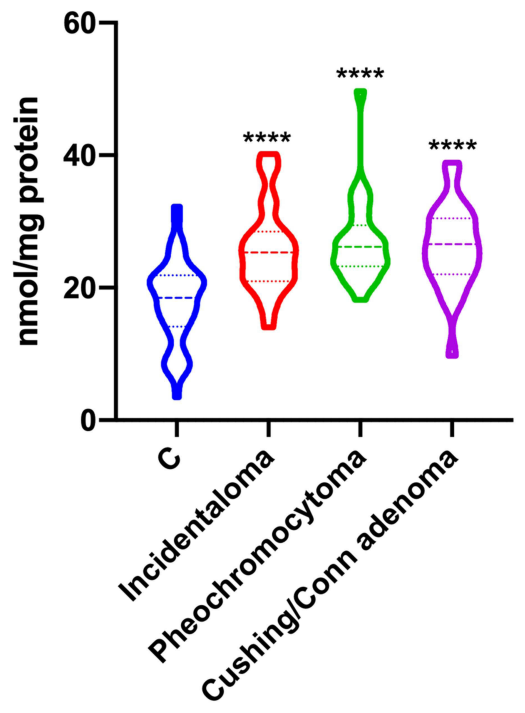

Plasma Peroxynitrite (ONOO')

Plasma concentration of $\mathrm{ONOO}^{-}$was increased only in Cushing's Conn's adenoma $(+62 \%, \mathrm{p}<0.0001)$ patients as compared to the controls. Moreover, the $\mathrm{ONOO}^{-}$plasma concentration in Cushing's Conn's adenoma subgroup was higher than incidentaloma $(+75 \%, p=0.0002)$ and pheochromocytoma $(+47 \%, \mathrm{p}=0.0097)$ subgroups. We also observed elevated peroxynitrite concentrations in $\mathrm{OB}$

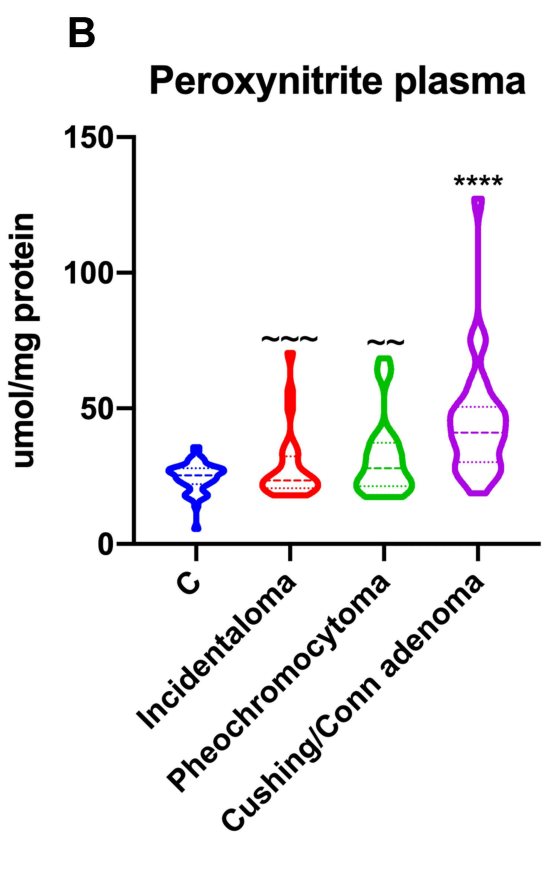

D

Nitrotyrosine plasma

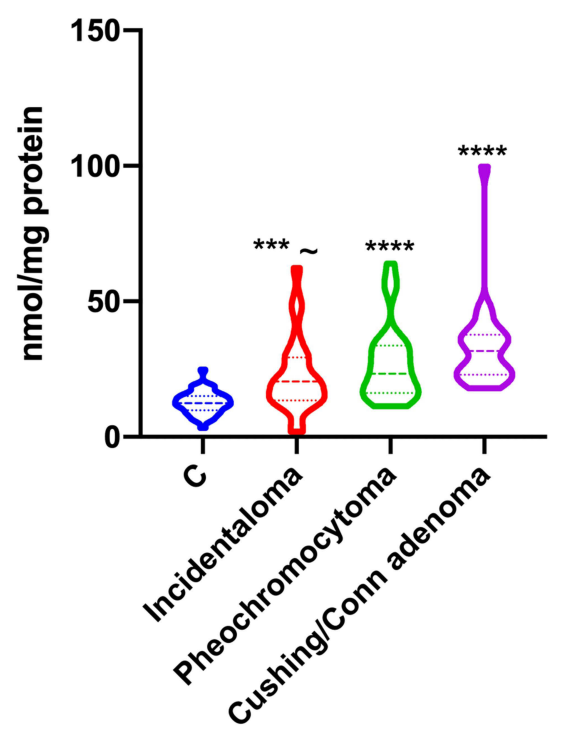

Figure I Violin plots of plasma total NO (A), ONOO- (B), S-nitrosothiols (C) and nitrotyrosine (D) of the control, incidentaloma, pheochromocytoma and Cushing's Conn's adenoma patients. Results are presented as median with $25 \%$ and $75 \%$ percentiles. $*^{*} p<0.01, * * * p<0.001, * * * * p<0.0001$ indicate significant differences from the controls; $\sim p<0.05, \sim p<0.01, \sim \sim p<0.001$ indicate significant differences from the Cushing's Conn's adenoma group; total nitric oxide (NO), peroxynitrite (ONOO'). 
+ HYP $(+44 \%, p=0.0011)$ and OB+MS $(+60 \%, p=0.0009)$ patients compared to $\mathrm{OB}$ ones (Figure 1B).

\section{Plasma S-Nitrosothiols}

We noticed greater plasma concentration of S-nitrosothiols in each group of adrenal masses patients: incidentaloma $(+37 \%, \mathrm{p}<0.0001)$, pheochromocytoma $(+42 \%, \mathrm{p}<0.0001)$ and Cushing's Conn's adenoma $(+44 \%, \mathrm{p}<0.0001)$ than the controls (Figure 1C).

\section{Plasma Nitrotyrosine}

Plasma nitrotyrosine concentration was greater in incidentaloma $(+64 \%, \mathrm{p}=0.0008)$, pheochromocytoma $(+88 \%$, $\mathrm{p}<0.0001)$ and Cushing's Conn's adenoma $(+154 \%$, $\mathrm{p}<0.0001)$ patients than the controls. Further on, we noticed that Cushing's Conn's adenoma $(+55 \%$, $\mathrm{p}=0.0218$ ) patients had increased plasma concentration of nitrotyrosine than incidentaloma patients (Figure 1D).

\section{Serum Myeloperoxidase (MPO)}

We observed higher plasma concentration of MPO in each group of adrenal masses patients: incidentaloma $(+39 \%$, $\mathrm{p}<0.0001)$, pheochromocytoma $(+41 \%, \mathrm{p}<0.0001)$ and Cushing's Conn's adenoma $(+42 \%, p<0.0001)$ in comparison with the controls (Figure 2A).

\section{Interleukin I Beta (IL-I $\beta$ )}

We observed that plasma concentration of IL- $1 \beta$ was significantly increased in patients with adrenal masses: incidentaloma $(+33 \%, \mathrm{p}=0.0002)$, pheochromocytoma $(+16 \%$, $\mathrm{p}=0.0099)$ and Cushing's Conn's adenoma $(+42 \%$, $\mathrm{p}<0.0001)$ patients in comparison with the controls (Figure 2B).

\section{Tumor Necrosis Factor $\alpha$ (TNF- $\alpha$ )}

Plasma concentration of TNF- $\alpha$ was greater in each group of adrenal masses patients: incidentaloma ( $+39 \%$, $\mathrm{p}<0.0001)$, pheochromocytoma $(+22 \%, \mathrm{p}=0.004)$ and Cushing's Conn's adenoma $(+33 \%, \mathrm{p}<0.0001)$ than the controls (Figure 2C).

\section{Hypoxia-Inducible Factor I Alpha (HIF-I $\alpha$ )} Plasma HIF-1 $\alpha$ concentration was markedly higher in incidentaloma $(+12 \%, \mathrm{p}=0.0002)$, pheochromocytoma $(+13 \%, \quad \mathrm{p}<0.0001)$ and Cushing's Conn's adenoma $(+18 \%, \mathrm{p}<0.0001)$ patients than the controls (Figure 2D).

\section{Correlations}

We found positive correlations between $\mathrm{ONOO}^{-}$and aldosterone ( $\mathrm{R}=0.337, \mathrm{p}=0.004)$, as well nitrotyrosine and aldosterone $(\mathrm{R}=0.41, \mathrm{p}<0.0001)$. NO total plasma concentration was associated positively with plasma $\mathrm{ONOO}^{-}$ $(\mathrm{R}=0.717, \mathrm{p}<0.0001)$, nitrotyrosine $(\mathrm{R}=0.434, \mathrm{p}<0.0001)$ and S-nitrosothiols $(\mathrm{R}=0.313, \mathrm{p}=0.006)$. Plasma $\mathrm{ONOO}^{-}$ correlated positively with nitrotyrosine $(\mathrm{R}=0.711$, $\mathrm{p}<0.0001)$ and S-nitrosothiols $(\mathrm{R}=0.314, \quad \mathrm{p}=0.006)$. Plasma nitrotyrosine was positively associated with S-nitrosothiols $(\mathrm{R}=0.23, \mathrm{p}=0.047)$.

Nitrosative stress was also associated with inflammation. We observed positive correlations $\mathrm{ONOO}^{-}$with $\mathrm{MPO}$ $(\mathrm{R}=0.591, \mathrm{p}<0.0001), \mathrm{IL}-1 \beta(\mathrm{R}=0.356, \mathrm{p}=0.002)$ and TNF$\alpha(\mathrm{R}=0.337, \mathrm{p}=0.003)$, as well as nitrotyrosine with MPO $(\mathrm{R}=0.338, \mathrm{p}=0.003), \mathrm{IL}-1 \beta(\mathrm{R}=0.598, \mathrm{p}<0.0001)$ and TNF- $\alpha$ $(\mathrm{R}=0.611, \mathrm{p}<0.0001)$. The positive correlations were also seen between total NO and MPO $(\mathrm{R}=0.441, \mathrm{p}<0.0001)$, and S-nitrosothiols and MPO $(\mathrm{R}=0.307, \mathrm{p}=0.007)$.

Interestingly, we also found correlations between hypoxia and nitrosative stress, inflammation and clinical parameters. The positive correlations were observed between HIF- $1 \alpha$ and $\mathrm{ONOO}^{-} \quad(\mathrm{R}=0.389, \quad \mathrm{p}=0.001), \quad$ nitrotyrosine $\quad(\mathrm{R}=0.636$, $\mathrm{p}<0.0001), \quad I L-1 \beta \quad(R=0.418, p<0.0001), T N F-\alpha \quad(R=0.514$, $\mathrm{p}<0.0001)$ and aldosterone $(\mathrm{R}=0.274, \mathrm{p}=0.019)$.

BMI was positively associated with serum concentration of glucose $(\mathrm{R}=0.253, \mathrm{p}=0.033)$ and negatively with urine metanephrine $(R=-0.339, p=0.003)$. Serum concentration of glucose correlated negatively with urine metanephrine $(\mathrm{R}=$ $-0.346, \mathrm{p}=0.003)$ and normetanephrine $(\mathrm{R}=-0.246$, $\mathrm{p}=0.0039$ ). We also observed positive correlations between aldosterone and urinary normetanephrine $(\mathrm{R}=0.261$, $\mathrm{p}=0.026)$, metanephrine and normetanephrine $(\mathrm{R}=0.246$, $\mathrm{p}<0.0001)$ and IL- $1 \beta$ and TNF- $\alpha(\mathrm{R}=0.78, \mathrm{p}<0.0001)$.

Correlations between nitrosative stress biomarkers and inflammation and clinical parameters are shown in Figure 3.

\section{Multivariate Regression Analysis}

Using multivariate regression analysis, we showed that concentration of $\mathrm{ONOO}^{-}$and IL- $1 \beta$ depend on cortisol level, while $\mathrm{ONOO}^{-}$, nitrotyrosine and HIF-1 $\alpha$ varies with aldosterone. Results of multifactorial regression analysis are shown in Table 2.

\section{ROC Analysis}

We also analyzed diagnostic usefulness of the estimated nitrosative stress and inflammatory biomarkers. The 
A

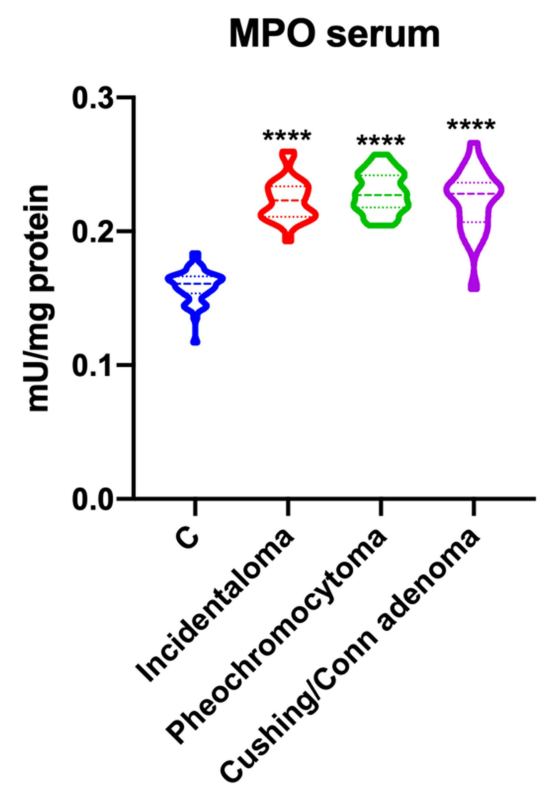

C

TNF-a plasma

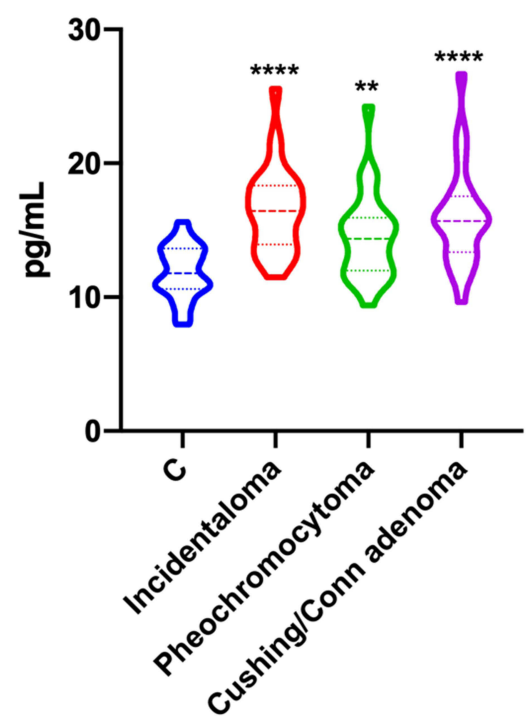

B

\section{IL-1B plasma}

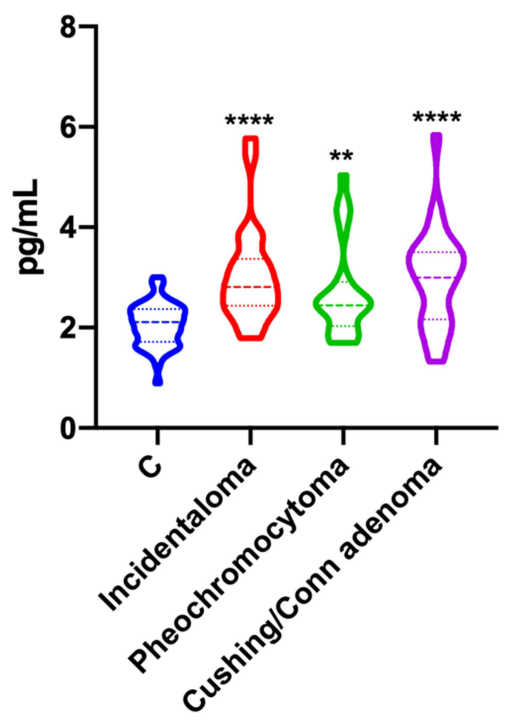

D

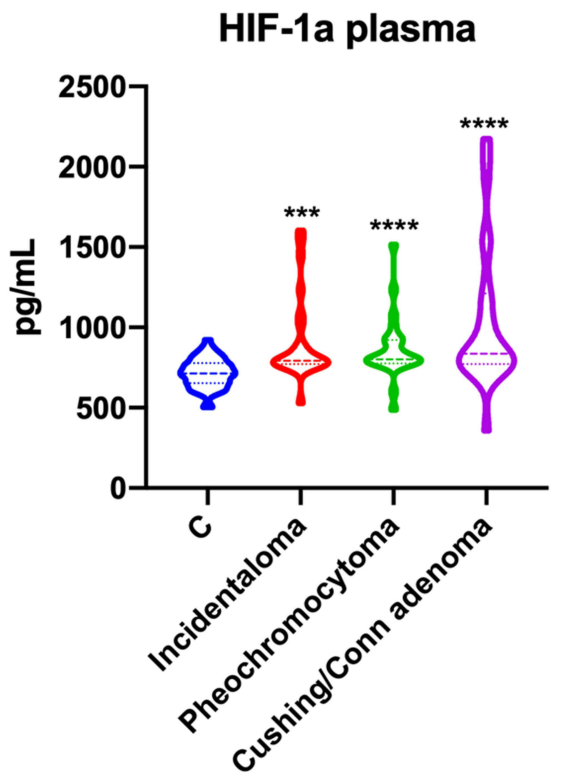

Figure 2 Violin plots of serum MPO (A), plasma IL-I $\beta$ (B), TNF- $\alpha(\mathbf{C})$ and HIF-I $\alpha(\mathbf{D})$ of the control, incidentaloma, pheochromocytoma and Cushing's Conn's adenoma patients. Results are presented as median with $25 \%$ and $75 \%$ percentiles. $*^{*} p<0.0$ I, $*_{* *}<<0.00$ I, $* * * * p<0.000$ I indicate significant differences from the controls; myeloperoxidase (MPO), interleukin I beta (IL-I $\beta$ ) and tumor necrosis factor $\alpha$ (TNF- $\alpha$ ).

results of ROC analysis are presented in Table 3. Interestingly, plasma nitrotyrosine and MPO with high sensitivity and specificity differentiates adrenal tumor patients from the healthy individuals (Table 3 ).

\section{Discussions}

The etiology of adrenal tumors is not well understood. Recent studies indicate that some patients are characterized by chromosomal abnormalities, deficiencies in growth factor production as well as diminished antioxidant barrier and higher oxidative stress level. ${ }^{36,43}$ However, the role of NO metabolites and their association with inflammatory molecules is still unknown in patients with adrenal tumors. This study is the first to demonstrate systemic nitrosative stress and inflammation in different types of adrenal masses. Additionally, we have shown that plasma nitrotyrosine 


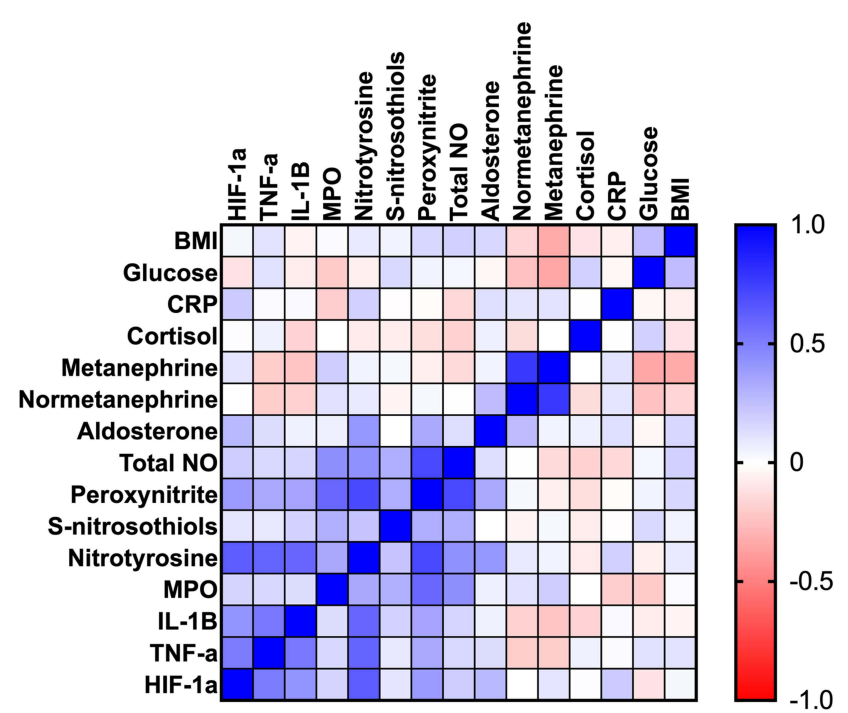

Figure 3 Correlation heat map between the analyzed nitrosative stress, inflammation and clinical parameters in serum and plasma of the patients with adrenal masses; body mass index (BMI), C reactive protein (CRP), nitric oxide (NO), myeloperoxidase (MPO), interleukin I beta (IL-I $\beta$ ), tumor necrosis factor $\alpha$ (TNF- $\alpha$ ) and hypoxia-inducible factor I alpha (HIF-I $\alpha$ ).

may be a potential biomarker differentiating healthy individuals from cases with incidentaloma, pheochromocytoma, and Cushing's/Conn's adenoma.

NO is an important signaling molecule involved in the regulation of many physiological processes. This compound also has a second face because, in a high concentration, NO exhibits strong cytotoxic properties. ${ }^{19,27,44}$ The biological activity of NO is mainly manifested by protein S-nitrosylation and tyrosine nitration. ${ }^{45}$ Therefore, in adrenal tumor patients, we observed not only increased NO formation, but also higher S-nitrosothiols and nitrotyrosine levels. NO may be a promoter of carcinogenic nitrosamines, while nitrosylation of primary arylamines is directly responsible for its mutagenic effects. ${ }^{46}$ It is believed that nitrosative damage to DNA and disruption of replication and transcription processes represent an early stage of tumor development. ${ }^{47}$ Nevertheless, NO may also contribute to tumorigenesis by suppressing the immune response and inducing angiogenesis. ${ }^{48}$ Indeed, cytokine-activated macrophages produce large amounts of NO, which increase, on a positive feedback, the formation of cytokines, chemokines, and growth factors. ${ }^{49}$ This may be confirmed by the positive correlation between $\mathrm{NO}$ and MPO in the adrenal tumor patients. Furthermore, nitric oxide reacting with superoxide radical generates peroxynitrite, which is the most potent oxidizing and nitrating agents. ${ }^{27,50}$ In our study, this may be confirmed by the positive correlation of $\mathrm{ONOO}^{-}$with nitrotyrosine and S-nitrosothiols. Although S-nitrosylation has important biological functions, the increased formation of S-nitrosothiols disrupts many enzymatic and structural proteins by forming protein disulfides and attaching nitroxyl moieties. ${ }^{51-53}$ Protein modified by nitrosative stress tend to form aggregates, which accumulate in tissues and reduce their susceptibility to proteolytic degradation. These complexes can also stimulate the NADPH oxidase (NOX) activity, which is the primary source of free radicals in the cell. ${ }^{54}$ NOX activation also increases the synthesis and release of inflammatory mediators, ${ }^{55}$ which may be supported by the positive relationship between S-nitrosothiols and MPO. However, NO-mediated mitochondrial dysfunction also has an important role in tumor induction and progression. NO has been shown to downregulation of glyceraldehyde-3-phosphate dehydrogenase activity (through S-nitrosylation and subsequent ADPribosylation), leading to inhibition of glycolysis and a decrease in ATP cellular level. ${ }^{56-59} \mathrm{ONOO}^{-}$can also suppress ATP synthesis by inhibiting mitochondrial aconitase in the citric acid cycle. Thus, the cytotoxic effects of NO are associated with inhibition of key cellular enzymes. ${ }^{60} \mathrm{ONOO}^{-}$may also exacerbate inflammation, ${ }^{32,61}$ as evidenced by a positive correlation with MPO, IL-1 $\beta$ and TNF- $\alpha$.

We also found elevated concentration of HIF-1 $\alpha$ in patients with adrenal tumors. HIF- $1 \alpha$ is a crucial transcription factor in cancer progression. ${ }^{15}$ HIF- $1 \alpha$ shows various effects depending on the oxygen supply. Under the physiological concentration of oxygen in cells, it is broken down by the ubiquitin-proteasome pathway (UPP). ${ }^{62}$ However, in hypoxic states, its accumulation is excessive, which leads to the dysregulation of many genes involved in the pathogenesis of cancer. It was shown that HIF-1 is activated under oxidative stress conditions. ${ }^{63}$ Indeed, high concentration of ROS produced in the mitochondria leads to stabilization of HIF-1 $1 .{ }^{64}$ Moreover, studies from recent years indicate that $\mathrm{NO}$ takes part in the stabilization of HIF-1 $\alpha$ directly by S-nitrosylation and indirectly by inhibition of procollagen-proline dioxygenase (PHDs). ${ }^{65,66}$ Precise cellular responses and protein activation may depend on various concentrations and duration of exposure to NO. ${ }^{67,68}$ The HIF-1 $\alpha$ response to NO exposure is immediate. NO can stabilize HIF-1 $\alpha$ only in concentrations above the threshold amount leading to its excessive accumulation. On the other hand, lowering the NO 


\begin{tabular}{|c|c|c|c|c|c|c|c|c|c|c|}
\hline & & 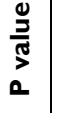 & $\begin{array}{l}\text { 员 } \\
\text { م. }\end{array}$ & $\begin{array}{l}\text { oे } \\
\text { ठ̊. }\end{array}$ & $\frac{\stackrel{h}{\hat{n}}}{\hat{i}}$ & $\begin{array}{l}\bar{y} \\
\text { ờ. } \\
0\end{array}$ & 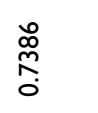 & 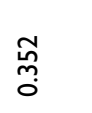 & $\begin{array}{l}\text { 今้ } \\
\text { ڤn' } \\
0\end{array}$ & $\begin{array}{l}\tilde{\tilde{o}} \\
\text { o. }\end{array}$ \\
\hline & 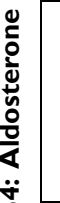 & $\begin{array}{l}\bar{u} \\
\stackrel{\circ}{\circ} \\
\text { ٌ }\end{array}$ & 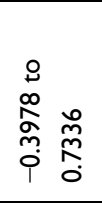 & 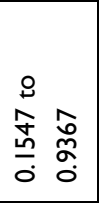 & 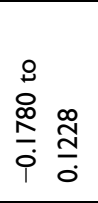 & 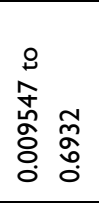 & 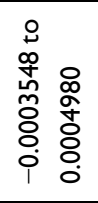 & 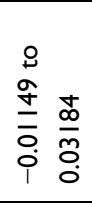 & 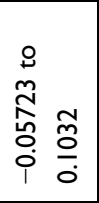 & 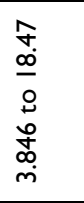 \\
\hline & & 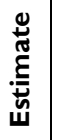 & $\frac{\sigma}{\hat{0}}$ & 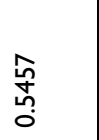 & 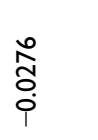 & 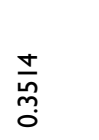 & $\begin{array}{l}\frac{0}{\hat{0}} \\
0 \\
0\end{array}$ & 승 & $\begin{array}{l}\text { సั } \\
\text { ठั. }\end{array}$ & $\stackrel{\circ}{\underline{=}}$ \\
\hline \multirow{3}{*}{\multicolumn{2}{|c|}{ 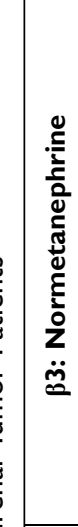 }} & 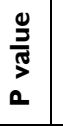 & 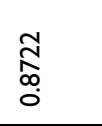 & 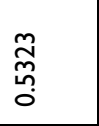 & $\begin{array}{l}\overline{0} \\
0 \\
0 \\
0\end{array}$ & $\begin{array}{l}\overline{\mathfrak{m}} \\
\stackrel{\alpha}{0}\end{array}$ & $\begin{array}{l}\stackrel{1}{\infty} \\
\stackrel{0}{0}\end{array}$ & $\frac{f}{0}$ & 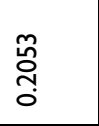 & $\frac{0}{\infty}$ \\
\hline & 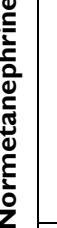 & $\begin{array}{l}\bar{u} \\
\stackrel{\circ}{\circ} \\
\text { นั }\end{array}$ & 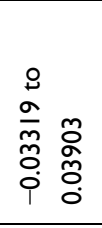 & 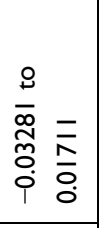 & 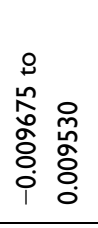 & 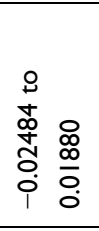 & 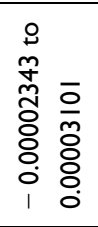 & 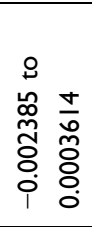 & 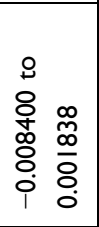 & 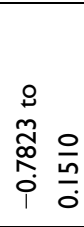 \\
\hline & & 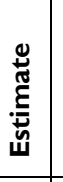 & 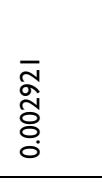 & $\begin{array}{l}\stackrel{n}{\infty} \\
\stackrel{0}{0} \\
0 \\
i\end{array}$ & 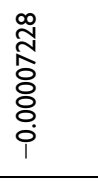 & $\begin{array}{l}\bar{\delta} \\
\text { Oे } \\
0 \\
i\end{array}$ & 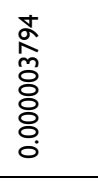 & $\begin{array}{l}\text { 긍 } \\
\text { 웅 }\end{array}$ & $\begin{array}{l}\bar{\infty} \\
\underset{\sim}{0} \\
\stackrel{0}{0} \\
\dot{\varphi}\end{array}$ & $\frac{\stackrel{\circ}{n}}{\text { ஸे }}$ \\
\hline \multirow{3}{*}{\multicolumn{2}{|c|}{ 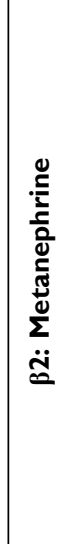 }} & 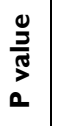 & :̊ণ্ণ & $\begin{array}{l}\frac{a}{2} \\
\frac{0}{0}\end{array}$ & 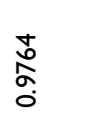 & $\begin{array}{l}\frac{\sigma}{\alpha} \\
\stackrel{\alpha}{0} \\
0\end{array}$ & $\frac{\square}{\frac{\vdots}{a}}$ & $\frac{\hat{o}}{\hat{N}}$ & $\begin{array}{l}\text { مे } \\
\stackrel{0}{0} \\
\text { o }\end{array}$ & $\begin{array}{l}\text { 今े } \\
\text { นh } \\
\text { م. }\end{array}$ \\
\hline & & 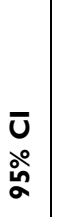 & 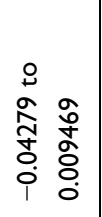 & 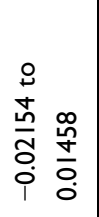 & 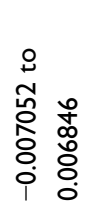 & 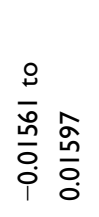 & 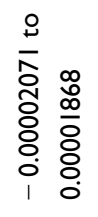 & 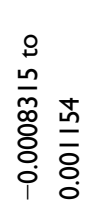 & 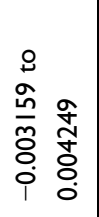 & 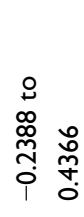 \\
\hline & & 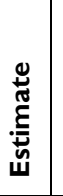 & $\begin{array}{l}\stackrel{\circ}{\circ} \\
\stackrel{\circ}{0} \\
0 \\
\end{array}$ & 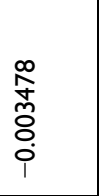 & $\begin{array}{l}\stackrel{0}{0} \\
\frac{0}{0} \\
0 \\
0\end{array}$ & $\begin{array}{l}\text { ळे } \\
\frac{\infty}{0} \\
\frac{0}{0}\end{array}$ & $\begin{array}{l}\frac{n}{0} \\
\frac{0}{0} \\
0 \\
0 \\
0\end{array}$ & $\frac{\frac{m}{0}}{\frac{0}{0}}$ & 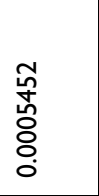 & 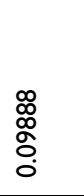 \\
\hline \multirow{3}{*}{\multicolumn{2}{|c|}{ 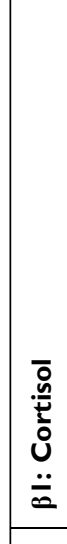 }} & $\begin{array}{l}\frac{0}{2} \\
\frac{0}{2} \\
\frac{D}{2}\end{array}$ & $\begin{array}{l}\hat{\alpha} \\
\text { o. } \\
0 \\
0\end{array}$ & $\begin{array}{l}\text { 宫 } \\
0 \\
0\end{array}$ & $\begin{array}{l}\frac{a}{0} \\
\stackrel{\circ}{0}\end{array}$ & 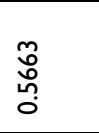 & $\begin{array}{l}\text { o. } \\
\stackrel{0}{\circ}\end{array}$ & 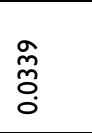 & $\begin{array}{l} \pm \\
\text { ¿ } \\
\text { o } \\
0\end{array}$ & 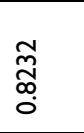 \\
\hline & & $\begin{array}{l}\bar{u} \\
\stackrel{\circ}{\circ} \\
\text { ڤั }\end{array}$ & 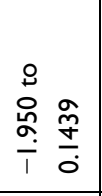 & 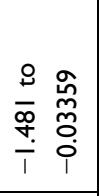 & 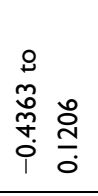 & 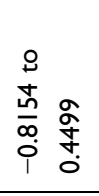 & 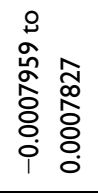 & 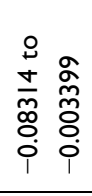 & 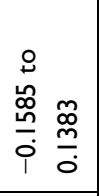 & 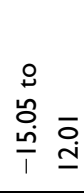 \\
\hline & & 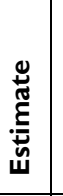 & $\begin{array}{l}\tilde{o} \\
\text { ळ. } \\
\text { ô }\end{array}$ & $\begin{array}{c}\stackrel{m}{n} \\
\hat{n} \\
\hat{i}\end{array}$ & $\frac{\substack{n \\
\text { in }}}{i}$ & $\frac{\widehat{D}}{\frac{\infty}{0}}$ & 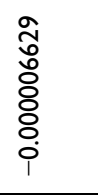 & 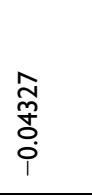 & $\begin{array}{l}\overline{0} \\
\text { 웅 }\end{array}$ & $\stackrel{\bar{n}}{\underline{i}}$ \\
\hline & 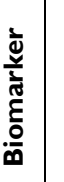 & & $\begin{array}{l}\stackrel{0}{z} \\
\frac{\pi}{0} \\
\stackrel{0}{\circ}\end{array}$ & 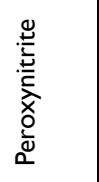 & 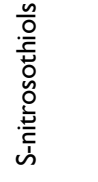 & 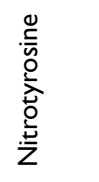 & $\frac{0}{2}$ & $\stackrel{\frac{m}{!}}{=}$ & $\underset{i}{\stackrel{i}{z}}$ & $\frac{\frac{\sigma}{\dot{1}}}{\frac{\mathrm{I}}{\mathrm{I}}}$ \\
\hline
\end{tabular}




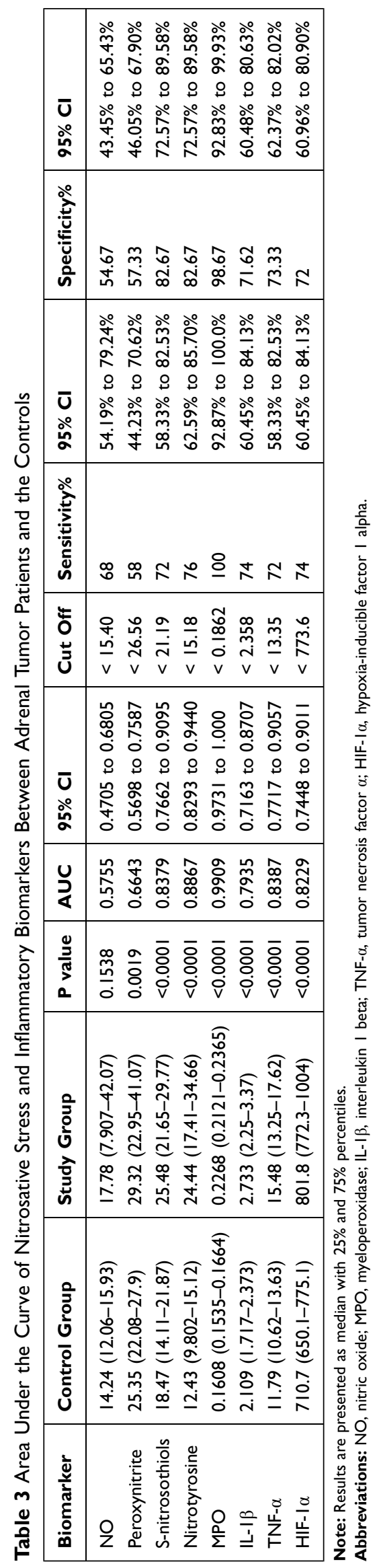

concentration below the minimum level leads to a decrease in the level and disappearance of HIF-1 $\alpha{ }^{68-70}$ The above statement may explain the positive correlations of HIF-1 $\alpha$ with $\mathrm{ONOO}^{-}$and nitrotyrosine in patients with adrenal tumors observed in our study. Additionally, we observed that HIF- $1 \alpha$ was positively associated with IL- $1 \beta$ and TNF- $\alpha$. Under hypoxic conditions, the activity of HIF- $1 \alpha$ is closely related to inflammation. ${ }^{71}$ It regulates the secretion of cytokines, the differentiation of monocytes into macrophages accompanied by the secretion of cytokines such as IL-1 $\beta$, IL-6, IL-12, IL-23 and TNF- $\alpha{ }^{72-74}$ It is important to note that HIF-1 $\alpha$ may be stabilized by inflammatory cytokines, especially TNF- $\alpha$, inducing positive feedback, stimulating further differentiation of monocytes into macrophage. ${ }^{71,75}$ Moreover, nuclear factor kappa B (NF-kB) plays a key role in the stabilization of HIF-1 $\alpha$ by TNF- $\alpha$, which intensifies HIF- $1 \alpha$-mediated inflammation under hypoxic conditions. ${ }^{71}$

Metabolic abnormalities accompanying adrenal masses may be responsible for increased inflammation and nitrosative stress. Semi-quinone radicals (formed in the oxidation of dopamine, epinephrine, and norepinephrine) have been shown to cause glutathione oxidation, lipoperoxidation, and DNA oxidative damage. ${ }^{36}$ This promotes the formation of inflammatory mediators and enhances NADPH oxidase activity, which is not only an important source of free radicals but also cytokines and chemokines. $^{76}$ Catabolism of catecholamines by MAO and COMT enzymes may also increase NO production and interleukin secretion. ${ }^{77}$ In our study, we also observed a higher BMI in patients with adrenal tumors compared to healthy controls. Although excessive catecholamine secretion leads to weight loss, it may also be involved in the development of obesity and metabolic disorders. ${ }^{7}$ Several studies have shown that catecholamines inhibit adiponectin secretion, which is significantly reduced in patients with adrenal masses. ${ }^{78-80}$ In transgenic mice with a deletion of the collagen domain of adiponectin, a lower concentration of circulating adiponectin was observed, which led to an increase in lipoprotein lipase activity and lipid removal. ${ }^{81}$ However, it should be noted that patients in the study group were only overweight but not obese.

Similarly, increased cortisol output may also disrupt redox homeostasis and inflammation. On the one hand, cortisol blocks cyclooxygenases (COX-1 and COX-2) responsible for the formation of prostaglandins and proteolytic enzymes (elastase and collagenase), impoverishing the phagocytosis process and protecting lysosomes against 
the release of degrading hydrolytic enzymes. ${ }^{82}$ However, this hormone also increases hepatocyte's sensitivity to adrenaline and glucagon as well as intensifies gluconeogenesis by stimulating phosphoenolpyruvate carboxykinase and glucose-6-phosphatase activities. ${ }^{83,84}$ Cortisol also enhances adipose tissue lipolysis with accompanying release of glycerol and free fatty acids into circulation. ${ }^{85}$ Therefore, it may be responsible for hyperglycemia and hyperlipidemia in adrenal masses patients. In our study, although glucose level was generally within reference values it was also significantly higher compared to controls. The highest glucose values were observed in patients with incidentaloma and Cushing's/Conn's adenoma. Therefore, metabolic abnormalities caused by higher cortisol/catecholamine output may be associated with systemic inflammation and nitrosative stress. ${ }^{86}$ However, this hypothesis requires further research and clinical observations.

An important part of the study was also to determine the diagnostic utility of nitrosative stress and inflammatory biomarkers. Diagnosis of adrenal tumors is based on imaging studies in conjunction with evaluation of blood/urine hormones such as cortisol, metanephrine, and normetanephrine. Therefore, biomarkers for early and non-invasive diagnosis of adrenal cancer are still being sought. Using ROC analysis, we demonstrated that circulating S-nitrosothiols, nitrotyrosine, and MPO differentiate controls from adrenal tumor patients with very high sensitivity $(>72 \%)$ and specificity $(>83 \%)$. Of particular note is nitrotyrosine, whose levels correlate not only with inflammatory markers (MPO, IL$1 \beta$, TNF- $\alpha$ ) but also with HIF- $1 \alpha$ and aldosterone. In a multivariate regression model, we showed that nitrotyrosine is a predictor of aldosterone levels, which also supports the diagnostic value of this biomarker. It should be noted that nitrotyrosine determination is simple and inexpensive and can be performed in a routine diagnostic laboratory. Unfortunately, none of the assessed biomarkers did not differentiate between tumor types, suggesting that the severity of nitrosative damage and inflammation are similar in patients with incidentaloma, pheochromocytoma, and Cushing's/Conn's adenoma.

Our study is the first to evaluate the association of adrenal masses with nitrosative/nitrative stress, inflammation and HIF-1 expression. Although NO metabolites and the inflammatory response may be involved in adrenal masses development, the exact mechanism is still unknown. Due to the lack of ethics committee approval, we could not conduct animal studies to make the conclusions more convincing. Further studies evaluating the role of redox imbalance, inflammation, and apoptosis in adrenal masses progression are needed.

\section{Conclusions}

1. Adrenal tumors are associated with increased protein nitration/S-nitrosylation and inflammation.

2. There is a need for molecular studies to explain disturbances in redox homeostasis, nitrosative stress, and inflammation in patients with adrenal tumors.

\section{Data Sharing Statement}

The original contributions presented in the study are included in the article. Further inquiries can be directed to the corresponding author.

\section{Ethics Statement}

The studies involving human participants were reviewed and approved by the Bioethics Committee of the Medical University of Bialystok (permission code: R-I-002/66/ 2015, APK.002.341.2020). Written informed consent to participate in this study was provided by the participants.

\section{Funding}

This work was granted by the Medical University of Bialystok, Poland (grant number: SUB/1/DN/21/003/ 1140, SUB/1/DN/21/002/3330). Dr. Mateusz Maciejczyk was supported by the Foundation for Polish Science (FNP).

\section{Disclosure}

The authors declare no conflicts of interest.

\section{References}

1. Song JH, Mayo-Smith WW. Incidentally discovered adrenal mass. Radiol Clin North Am. 2011;49(2):361-368. doi:10.1016/j. rcl.2010.10.006

2. Nieman LK. Approach to the patient with an adrenal incidentaloma. J Clin Endocrinol Metab. 2010;95(9):4106-4113. doi:10.1210/ jc. $2010-0457$

3. Mansmann G, Lau J, Balk E, Rothberg M, Miyachi Y, Bornstein SR. The clinically inapparent adrenal mass: update in diagnosis and management. Endocr Rev. 2004;25(2):309-340. doi:10.1210/er.2002-0031

4. Grumbach MM, Biller BMK, Braunstein GD, et al. Management of the clinically inapparent adrenal mass ("incidentaloma"). Ann Intern Med. 2003;138(5):424. doi:10.7326/0003-4819-138-5-200303040-00013

5. Jason DS, Oltmann SC. Evaluation of an adrenal incidentaloma. Surg Clin North Am. 2019;99(4):721-729. doi:10.1016/j.suc.2019.04.009

6. Bhoster IR, Hill H, Greenfield JG. The adrenogenital syndrome associated with cortical hyperplasia; the results of unilateral adrenalectomy. $\quad B r \quad J \quad$ Surg. 1932;19:557-570. doi:10.1002/ bjs. 1800197606 
7. Erlic Z, Beuschlein F. Metabolic alterations in patients with pheochromocytoma. Exp Clin Endocrinol Diabetes. 2019;127(203):129-136. doi:10.1055/a-0649-0960

8. Tong C, England P, Champion de Crespigny P, Millar R, Conn J. Diabetes mellitus as the only manifestation of occult phaeochromocytoma prior to acute haemorrhage in pregnancy. Aust $N$ Zeal J Obstet Gynaecol. 2005. doi:10.1111/j.1479-828X.2005.00344.x

9. Lee JM, Kim MK, Ko SH, et al. Clinical guidelines for the management of adrenal incidentaloma. Endocrinol Metab. 2017;32(2):200. doi:10.3803/EnM.2017.32.2.200

10. Yozamp N, Vaidya A. Assessment of mild autonomous cortisol secretion among incidentally discovered adrenal masses. Best Pract Res Clin Endocrinol Metab. 2021;35(1):101491. doi:10.1016/j. beem.2021.101491

11. Pieroni J, Yamazaki Y, Gao X, et al. Cellular senescence in human aldosterone-producing adrenocortical cells and related disorders. Biomedicines. 2021;9(5):567. doi:10.3390/biomedicines9050567

12. Taïeb D, Pacak K. Genetic determinants of pheochromocytoma and paraganglioma imaging phenotypes. $J$ Nucl Med. 2020;61 (5):643-645. doi:10.2967/jnumed.120.245613

13. Martucci VL, Pacak K. Pheochromocytoma and paraganglioma: diagnosis, genetics, management, and treatment. Curr Probl Cancer. 2014;38(1):7-41. doi:10.1016/j.currproblcancer.2014.01.001

14. Fishbein L, Leshchiner I, Walter V, et al. Comprehensive molecular characterization of pheochromocytoma and paraganglioma. Cancer Cell. 2017;31(2):181-193. doi:10.1016/j.ccell.2017.01.001

15. Wigerup C, Påhlman S, Bexell D. Therapeutic targeting of hypoxia and hypoxia-inducible factors in cancer. Pharmacol Ther. 2016;164:152-169. doi:10.1016/j.pharmthera.2016.04.009

16. Zińczuk J, Maciejczyk M, Zaręba K, et al. Antioxidant barrier, redox status, and oxidative damage to biomolecules in patients with colorectal cancer. can malondialdehyde and catalase be markers of colorectal cancer advancement? Biomolecules. 2019;9(10):637. doi:10.3390/biom9100637

17. Mena S, Ortega A, Estrela JM. Oxidative stress in environmental-induced carcinogenesis. Mutat Res Genet Toxicol Environ Mutagen. 2009;674(1-2):36-44. doi:10.1016/j.mrgentox.20 08.09.017

18. Poprac P, Jomova K, Simunkova M, Kollar V, Rhodes CJ, Valko M. Targeting free radicals in oxidative stress-related human diseases. Trends Pharmacol Sci. 2017;38(7):592-607. doi:10.1016/j. tips.2017.04.005

19. Lushchak VI. Free radicals, reactive oxygen species, oxidative stress and its classification. Chem Biol Interact. 2014;224c:164-175. doi:10.1016/j.cbi.2014.10.016

20. Ługowski M, Saczko J, Julita Kulbacka TB. Reactive oxygen and nitrogen species. Pol Merkur Lek. 2011;31(185):313-317.

21. Supruniuk E, Maciejczyk M, Zalewska A, Górski J, Chabowski A. Blood profile of cytokines, chemokines, growth factors, and redox biomarkers in response to different protocols of treadmill running in rats. Int J Mol Sci. 2020;21(21):8071. doi:10.3390/ijms21218071

22. Skutnik-Radziszewska A, Maciejczyk M, Flisiak I, et al. Enhanced inflammation and nitrosative stress in the saliva and plasma of patients with plaque psoriasis. J Clin Med. 2020;9(3):745. doi: $10.3390 / \mathrm{jcm} 9030745$

23. Förstermann U. Oxidative stress in vascular disease: causes, defense mechanisms and potential therapies. Nat Clin Pract Cardiovasc Med. 2008;5(6):338-349. doi:10.1038/ncpcardio1211

24. Subramaniam R, Fan XJ, Scivittaro V, et al. Cellular oxidant stress and advanced glycation endproducts of albumin: caveats of the dichlorofluorescein assay. Arch Biochem Biophys. 2002;400 (1):15-25. doi:10.1006/abbi.2002.2776

25. Stadtman ER, Levine RL. Free radical-mediated oxidation of free amino acids and amino acid residues in proteins. Amino Acids. 2003;25(3-4):207-218. doi:10.1007/s00726-003-0011-2
26. Alvarez B, Radi R. Peroxynitrite reactivity with amino acids and proteins. Amino Acids. 2003;25(3-4):295-311. doi:10.1007/s00726003-0018-8

27. Lufrano M, Balazy M. Interactions of peroxynitrite and other nitrating substances with human platelets: the role of glutathione and peroxynitrite permeability. Biochem Pharmacol. 2003;65 (4):515-523. doi:10.1016/S0006-2952(02)01584-8

28. Ghezzi P, Bonetto V. Redox proteomics: identification of oxidatively modified proteins. Proteomics. 2003;3(7):1145-1153. doi:10.1002/ pmic. 200300435

29. Aulak KS, Miyagi M, Yan L, et al. Proteomic method identifies proteins nitrated in vivo during inflammatory challenge. Proc Natl Acad Sci U S A. 2001;98(21):12056-12061. doi:10.1073/ pnas. 221269198

30. Matough FA, Budin SB, Hamid ZA, Alwahaibi N, Mohamed J. The role of oxidative stress and antioxidants in diabetic complications. Sultan Qaboos Univ Med J. 2012;12(1):5-18. doi:10.12816/0003082

31. Maciejczyk M, Taranta-Janusz K, Wasilewska A, Kossakowska A, Zalewska A. A case-control study of salivary redox homeostasis in hypertensive children. can salivary uric acid be a marker of hypertension? J Clin Med. 2020;9(3):837. doi:10.3390/jcm9030837

32. Pacher P, Beckman JS, Liaudet L. Nitric oxide and peroxynitrite in health and disease. Physiol Rev. 2007;87(1):315-424. doi:10.1152/ physrev.00029.2006

33. Förstermann U, Sessa WC. Nitric oxide synthases: regulation and function. Eur Heart J. 2012;33(7):829-837. doi:10.1093/eurheartj/ ehr304

34. Maciejczyk M, Szulimowska J, Taranta-Janusz K, Wasilewska A, Zalewska A. Salivary gland dysfunction, protein glycooxidation and nitrosative stress in children with chronic kidney disease. J Clin Med. 2020;9(5):1285. doi:10.3390/jcm9051285

35. Karin M. NF-kappaB as a critical link between inflammation and cancer. Cold Spring Harb Perspect Biol. 2009;1(5):a000141a000141. doi:10.1101/cshperspect.a000141

36. Choromańska B, Myśliwiec P, Kozłowski T, et al. Antioxidant barrier and oxidative damage to proteins, lipids, and DNA/RNA in adrenal tumor patients. Oxid Med Cell Longev. 2021;2021:5543531. doi:10.1155/2021/5543531

37. Choromańska B, Myśliwiec P, Łuba M, et al. The impact of hypertension and metabolic syndrome on nitrosative stress and glutathione metabolism in patients with morbid obesity. Oxid Med Cell Longev. 2020;2020:1-10. doi:10.1155/2020/1057570

38. Grisham MB, Johnson GG, Lancaster JR. Quantitation of nitrate and nitrite in extracellular fluids. Methods Enzymol. 1996;268:237-246. doi:10.1016/s0076-6879(96)68026-4

39. Borys J, Maciejczyk M, Antonowicz B, et al. Glutathione metabolism, mitochondria activity, and nitrosative stress in patients treated for mandible fractures. J Clin Med. 2019;8(1):127. doi:10.3390/ jcm8010127

40. Wink DA, Kim S, Coffin D, et al. Detection of S-nitrosothiols by fluorometric and colorimetric methods. Methods Enzymol. 1999;301:201-211. doi:10.1016/S0076-6879(99)01083-6

41. Beckman JS, Ischiropoulos H, Zhu L, et al. Kinetics of superoxide dismutase- and iron-catalyzed nitration of phenolics by peroxynitrite. Arch Biochem Biophys. 1992;298(2):438-445. doi:10.1016/00039861(92)90432-V

42. Kruidenier L, Kuiper I, van Duijn W, et al. Imbalanced secondary mucosal antioxidant response in inflammatory bowel disease. J Pathol. 2003;201(1):17-27. doi:10.1002/path.1408

43. Vaidya A, Flores SK, Cheng Z-M, et al. EPAS1 mutations and paragangliomas in cyanotic congenital heart disease. $N$ Engl J Med. 2018;378(13):1259-1261. doi:10.1056/nejmc1716652

44. Förstermann U. Nitric oxide and oxidative stress in vascular disease. Pflugers Arch Eur J Physiol. 2010;459(6):923-939. doi:10.1007/ s00424-010-0808-2 
45. Wiseman DA, Thurmond DC. The good and bad effects of cysteine S-nitrosylation and tyrosine nitration upon insulin exocytosis: a balancing act. Curr Diabetes Rev. 2012;8(4):303-315. doi:10.2174/157339912800840514

46. Montenegro MF, Sundqvist ML, Nihlén C, et al. Profound differences between humans and rodents in the ability to concentrate salivary nitrate: implications for translational research. Redox Biol. 2016;10:206-210. doi:10.1016/j.redox.2016.10.011

47. Khan FH, Dervan E, Bhattacharyya DD, McAuliffe JD, Miranda KM, Glynn SA. The role of nitric oxide in cancer: master regulator or not? Int J Mol Sci. 2020;21(24):9393. doi:10.3390/ ijms 21249393

48. Zou D, Li Z, Lv F, et al. Pan-cancer analysis of NOS3 identifies its expression and clinical relevance in gastric cancer. Front Oncol. 2021;11:592761. doi:10.3389/fonc.2021.592761

49. Palmieri EM, McGinity C, Wink DA, McVicar DW. Nitric oxide in macrophage immunometabolism: hiding in plain sight. Metabolites. 2020;10(11):429. doi:10.3390/metabo10110429

50. Toczewska J, Konopka T, Zalewska A, Maciejczyk M. Nitrosative stress biomarkers in the non-stimulated and stimulated saliva, as well as gingival crevicular fluid of patients with periodontitis: review and clinical study. Antioxidants. 2020;9(3). doi:10.3390/antiox9030259

51. Fernando V, Zheng X, Walia Y, Sharma V, Letson J, Furuta S. S-nitrosylation: an emerging paradigm of redox signaling. Antioxidants (Basel, Switzerland). 2019;8(9):404. doi:10.3390/ antiox 8090404

52. Jourd'Heuil D, Hallén K, Feelisch M, Grisham MB. Dynamic state of S-nitrosothiols in human plasma and whole blood. Free Radic Biol Med. 2000;28(3):409-417. doi:10.1016/S0891-5849(99)00257-9

53. Drygalski K, Siewko K, Chomentowski A, et al. Phloroglucinol strengthens the antioxidant barrier and reduces oxidative/nitrosative stress in Nonalcoholic Fatty Liver Disease (NAFLD). Oxid Med Cell Longev. 2021;2021:1-18. doi:10.1155/2021/8872702

54. Żebrowska E, Chabowski A, Zalewska A, Maciejczyk M. High-sugar diet disrupts hypothalamic but not cerebral cortex redox homeostasis. Nutrients. 2020;12(10):3181. doi:10.3390/nu12103181

55. Maciejczyk M, Gerreth P, Zalewska A, Hojan K, Gerreth K. Salivary gland dysfunction in stroke patients is associated with increased protein glycoxidation and nitrosative stress. Oxid Med Cell Longev. 2020;2020:6619439. doi:10.1155/2020/6619439

56. Szabó C, Módis K. Pathophysiological roles of peroxynitrite in circulatory shock. Shock. 2010;34 Suppl 1(01):4-14. doi:10.1097/ SHK.0b013e3181e7e9ba

57. Sang J, Chen Y, Tao Y. Nitric oxide inhibits gastric cancer cell growth through the modulation of the Akt pathway. Mol Med Rep. 2011;4(6):1163-1167. doi:10.3892/mmr.2011.535

58. Kielbik M, Klink M, Brzezinska M, Szulc I, Sulowska Z. Nitric oxide donors: spermine/NO and diethylenetriamine/NO induce ovarian cancer cell death and affect STAT3 and AKT signaling proteins. Nitric Oxide. 2013;35:93-109. doi:10.1016/j.niox.2013.09.001

59. Zhang J-Y, Zhang F, Hong C-Q, et al. Critical protein GAPDH and its regulatory mechanisms in cancer cells. Cancer Biol Med. 2015;12 (1):10-22. doi:10.7497/j.issn.2095-3941.2014.0019

60. Pacher P, Szabo C. Role of the peroxynitrite-poly(ADP-ribose) polymerase pathway in human disease. Am J Pathol. 2008;173(1):2-13. doi:10.2353/ajpath.2008.080019

61. Klimiuk A, Zalewska A, Knapp M, Sawicki R, Ładny JR, Maciejczyk M. Salivary gland dysfunction in patients with chronic heart failure is aggravated by nitrosative stress, as well as oxidation and glycation of proteins. Biomolecules. 2021;11(1):1-27. doi:10.3390/biom 11010119

62. Rashid M, Zadeh LR, Baradaran B, et al. Up-down regulation of HIF-1 $\alpha$ in cancer progression. Gene. 2021;798:145796. doi:10.1016/ j.gene.2021.145796
63. Valko M, Rhodes CJ, Moncol J, Izakovic M, Mazur M. Free radicals, metals and antioxidants in oxidative stress-induced cancer. Chem Biol Interact. 2006;160(1):1-40. doi:10.1016/j.cbi.2005.12.009

64. Movafagh S, Crook S, Vo K. Regulation of hypoxia-inducible factor-1a by reactive oxygen species: new developments in an old debate. J Cell Biochem. 2015;116(5):696-703. doi:10.1002/jcb.25074

65. Li F, Sonveaux P, Rabbani ZN, et al. Regulation of HIF-1 $\alpha$ Stability through S-Nitrosylation. Mol Cell. 2007;26(1):63-74. doi:10.1016/j. molcel.2007.02.024

66. Metzen E, Zhou J, Jelkmann W, Fandrey J, Brüne B. Nitric oxide impairs normoxic degradation of HIF-1 $\alpha$ by inhibition of prolyl hydroxylases. Mol Biol Cell. 2003;14(8):3470-3481. doi:10.1091/ mbc.e02-12-0791

67. Paul SAM, Simons JW, Mabjeesh NJ. HIF at the crossroads between ischemia and carcinogenesis. J Cell Physiol. 2004;200(1):20-30. doi: $10.1002 /$ jcp. 10479

68. Thomas DD, Espey MG, Ridnour LA, et al. Hypoxic inducible factor 1alpha, extracellular signal-regulated kinase, and p53 are regulated by distinct threshold concentrations of nitric oxide. Proc Natl Acad Sci U S A. 2004;101(24):8894-8899. doi:10.1073/pnas.0400453101

69. Thomas DD, Espey MG, Pociask DA, Ridnour LA, Donzelli S, Wink DA. Asbestos redirects nitric oxide signaling through rapid catalytic conversion to nitrite. Cancer Res. 2006;66(24):11600LP11604. doi:10.1158/0008-5472.CAN-06-1140

70. Thomas DD, Ridnour LA, Isenberg JS, et al. The chemical biology of nitric oxide: implications in cellular signaling. Free Radic Biol Med. 2008;45(1):18-31. doi:10.1016/j.freeradbiomed.2008.03.020

71. Pena E, Brito J, El Alam S, Siques P. Oxidative stress, kinase activity and inflammatory implications in right ventricular hypertrophy and heart failure under hypobaric hypoxia. Int J Mol Sci. 2020;21 (17):6421. doi:10.3390/ijms21176421

72. Hohensinner PJ, Kaun C, Rychli K, et al. Monocyte chemoattractant protein (MCP-1) is expressed in human cardiac cells and is differentially regulated by inflammatory mediators and hypoxia. FEBS Lett. 2006;580(14):3532-3538. doi:10.1016/j.febslet.2006.05.043

73. Li X, Zhang Q, Nasser MI, et al. Oxygen homeostasis and cardiovascular disease: a role for HIF? Biomed Pharmacother. 2020;128:110338. doi:10.1016/j.biopha.2020.110338

74. Mil KM, Gryciuk ME, Pawlukianiec C, et al. Pleiotropic properties of Valsartan: do they result from the antiglycooxidant activity? Literature review and in vitro study. Oxid Med Cell Longev. 2021;2021:5575545. doi:10.1155/2021/5575545

75. Westra J, Brouwer E, Bos R, et al. Regulation of cytokine-induced HIF-1 $\alpha$ expression in rheumatoid synovial fibroblasts. Ann N Y Acad Sci. 2007;1108(1):340-348. doi:10.1196/annals.1422.035

76. Anna Z, Joanna K, Sara Z, et al. N-acetylcysteine supplementation did not reverse mitochondrial oxidative stress, apoptosis, and inflammation in the salivary glands of hyperglycemic rats. Nutr Diabetes. 2021;11(1):35. doi:10.1038/s41387-021-00177-w

77. Siraki AG, O'Brien PJ. Prooxidant activity of free radicals derived from phenol-containing neurotransmitters. Toxicology. 2002;177 (1):81-90. doi:10.1016/S0300-483X(02)00197-X

78. Delporte M-L, Funahashi T, Takahashi M, Matsuzawa Y, Brichard SM. Pre- and post-translational negative effect of beta-adrenoceptor agonists on adiponectin secretion: in vitro and in vivo studies. Biochem J. 2002;367(Pt 3):677-685. doi:10.1042/ BJ20020610

79. Letizia C, Petramala L, Di Gioia CRT, et al. Leptin and adiponectin mRNA expression from the adipose tissue surrounding the adrenal neoplasia. J Clin Endocrinol Metab. 2015;100(1):E101-E104. doi:10.1210/jc.2014-2274

80. Babinska A, Kaszubowski M, Sworczak K. Adipokine and cytokine levels in non-functioning adrenal incidentalomas (NFAI). Endocr $J$. 2018;65(8):849-858. doi:10.1507/endocrj.EJ18-0066 
81. Combs TP, Berg AH, Obici S, Scherer PE, Rossetti L. Endogenous glucose production is inhibited by the adipose-derived protein Acrp30. J Clin Invest. 2001;108(12):1875-1881. doi:10.1172/JCI14120

82. Bin Rubaia'an MA, Alotaibi MK, Alotaibi NM, Alqhtani NR. Cortisol in oral and maxillofacial surgery: a double-edged sword. Int J Dent. 2021;2021:7642875. doi:10.1155/2021/7642875

83. Rahimi L, Rajpal A, Ismail-Beigi F. Glucocorticoid-induced fatty liver disease. Diabetes Metab Syndr Obes. 2020;13:1133-1145. doi:10.2147/DMSO.S247379
84. Thuzar M, Stowasser M. The mineralocorticoid receptor-an emerging player in metabolic syndrome? J Hum Hypertens. 2021;35 (2):117-123. doi:10.1038/s41371-020-00467-3

85. Arnaldi G, Scandali VM, Trementino L, Cardinaletti M, Appolloni G, Boscaro M. Pathophysiology of dyslipidemia in Cushing's syndrome. Neuroendocrinology. 2010;92(Suppl. 1):86-90. doi:10.1159/ 000314213

86. Kershaw EE, Flier JS. Adipose tissue as an endocrine organ. $J$ Clin Endocrinol Metab. 2004;89(6):2548-2556. doi:10.1210/jc.2004-0395
Journal of Inflammation Research

\section{Publish your work in this journal}

The Journal of Inflammation Research is an international, peerreviewed open-access journal that welcomes laboratory and clinical findings on the molecular basis, cell biology and pharmacology of inflammation including original research, reviews, symposium reports, hypothesis formation and commentaries on: acute/chronic inflammation; mediators of inflammation; cellular processes; molecular
Dovepress

mechanisms; pharmacology and novel anti-inflammatory drugs; clinical conditions involving inflammation. The manuscript management system is completely online and includes a very quick and fair peerreview system. Visit http://www.dovepress.com/testimonials.php to read real quotes from published authors. 